\title{
UMA ANÁLISE DA RESISTÊNCIA AO PRECEITO DA MUNICIPALIZAÇÃO DO ENSINO
}

\author{
Angela Maria de Souza Lima \\ Mestre em sociologia pela UFPR \\ e docente de Ciências Sociais na UEL
}

E-mail: marinasoli@aol.com

\section{Resumo}

$\mathrm{O}$ artigo pretende analisar o processo de municipalização do ensino fundamental em Londrina, a partir da segunda metade da década de 90 , e, sobretudo, o processo de resistência a essa política descentralizatória, empreendida pelos atores sociais, organizados através de suas entidades representativas e por meio da Secretaria Municipal de Educação. A análise nos auxilia na compreensão das relações de poder local, das peculiaridades da política educacional do município e das aproximações dessa política às reformas de descentralização estimuladas no âmbito nacional e estadual.

Palavras-chave: municipalização; poder local; descentralização política.

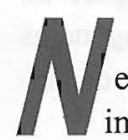

este artigo, o estudo dos conflitos e da resistência em torno da implantação do processo da municipalização do ensino fundamental de $1^{\text {a }}$ a $4^{\text {a }}$. série em Londrina, a partir da segunda metade da década de 90, é nosso principal foco de análise. Analisando especificamente o caso londrinense, pensamos poder compreender melhor como a municipalização do ensino é proposta e encaminhada no município, como é percebida pela sociedade civil organizada através dos sindicatos, fóruns e conselhos e avaliada pelas entidades de representação do 
governo estadual e municipal (Secretarias de Educação e Núcleo Regional de Educação), que conflitos se estabelecem entre as diferentes instâncias de poder e por que estes são gerados e mantidos.

Pensamos que os resultados da pesquisa, uma vez contextualizados na política educacional vigente no país e no Paraná, podem auxiliar-nos na apreensão das relações de poder local, na compreensão de como os conflitos socioeducacionais e sociopolíticos se dão na concretude da vida cotidiana e da prática dos agentes locais, das organizações e dos grupos de pressão por eles constituídos.

Há uma relação de aproximação, tanto teórica como prática, entre os processos de municipalização do ensino fundamental de $1^{\mathrm{a}}$. a $4^{\mathrm{a}}$. série em Londrina e as questões referentes à municipalização do ensino no Paraná e no Brasil como um todo, assim como há peculiaridades, tanto políticas quanto educacionais, que só um estudo mais apurado do caso londrinense pode desvendar.

Preliminarmente, essa aproximação explica-se por três fatores básicos. Primeiro porque, em grande parte, a resistência dos grupos de pressão, contrários à municipalização em Londrina ou à sua forma de implementação, se dá no âmbito estadual (APP-Sindicato e Fórum em Defesa da Escola Pública) e, em menor parte, no âmbito municipal (SINDSERV e Conselho Municipal de Educação de Londrina). Segundo, porque os projetos e ações governamentais que regulamentam a municipalização em Londrina fazem parte, ora do contexto estadual, ora do contexto das políticas públicas federais, mais propriamente de ambos, ao mesmo tempo. Terceiro, não há como fazer uma análise da municipalização em Londrina, desvinculada da análise das políticas públicas brasileiras e paranaenses que por sua vez sofrem, no período em questão, fortes pressões econômicas e ideológicas das agências internacionais de fiscalização e financiamento, fato que não nos atemos a analisar neste trabalho.

\section{Uma história de resistência}

Londrina faz parte do Núcleo Regional de Educação de Londrina, composto por dezenove cidades. Assim como outras cidades de 
médio e grande porte no Paraná, como: Curitiba, Ponta Grossa, Maringá, Cascavel e Foz do Iguaçu, por exemplo, ela não aderiu, de início, ao processo de municipalização do ensino fundamental. O município enquadra-se no que podemos chamar de "Resistência à Municipalização", tendo ainda 36 escolas de $1^{\text {a }}$. a $4^{\mathrm{a}}$. série do ensino fundamental pertencentes à rede estadual.

Grande parte das cidades paranaenses já aderiram à municipalização. O município de Rolândia municipalizou sucessivamente toda a rede de ensino de $1^{\mathrm{a}}$.a $4^{\mathrm{a}}$. série nos últimos quatro anos, que contou, em 2002, com 4.197 alunos. O município de Ibiporã municipalizou em 2001, de uma só vez, todas as escolas de $1^{\mathrm{a}}$. a $4^{\mathrm{a}}$. série, contabilizando, em 2002, 3.677 alunos do ensino fundamental (LONDRINA: Núcleo Regional de Educação, 2002).

Na segunda metade da década de 90 , são exceções os municípios que não se enquadram na municipalização total. Cambé possui apenas uma escola municipalizada; 8.029 alunos do ensino fundamental em 2002 ainda pertencem ao estado. O município de Prado Ferreira não aderiu à municipalização; em 2002 contava ainda com 277 alunos de $1^{\text {a }}$. a $4^{\text {a }}$. série em escolas estaduais e apenas 16 alunos em escolas municipais. Todas as salas de pré-escola e educação especial continuam com a rede estadual (LONDRINA. Núcleo Regional de Educação, 2002).

No quadro listado abaixo mostraremos o mapa da municipalização do ensino fundamental no Brasil, apresentado pela pesquisa do MEC em 1998: percentual de municípios.

\section{Tebela 1}

Mapa da Municipalização do Ensino Fundamental no Brasil

\begin{tabular}{l|c|c|c|c} 
REGIÃO & $\begin{array}{c}\text { COM } \\
\text { MUNICIPALIZAÇÄO }\end{array}$ & $\begin{array}{c}\text { SEM } \\
\text { MUNICIPALIZAÇÄO }\end{array}$ & $\begin{array}{c}\text { SEM } \\
\text { INFORMAÇÃO }\end{array}$ & TOTAL \\
\hline Brasil & 28,1 & 66,0 & 6,0 & 100,0 \\
Norte & 4,4 & 85,6 & 10,0 & 100,0 \\
Nordeste & 18,5 & 78,0 & 4,4 & 100,0 \\
Sudeste & 57,6 & 31,0 & 12,0 & 100,0 \\
Sul & 37,6 & 59,0 & 3,3 & 100,0 \\
Centro-oeste & 13,0 & 83.0 & 4,3 & 100,0
\end{tabular}


A pesquisa, segundo levantamentos do $\operatorname{MEC}$ (1999), indica que $28,1 \%$ dos municípios declararam ter assumido escolas estaduais ao longo de 1998. Esse movimento é mais intenso na região Sudeste, onde se constatou que $57,6 \%$ dos municípios assumiram escolas do ensino fundamental antes pertencentes à rede estadual.

De acordo com o MEC (1999), o processo de municipalização do ensino fundamental era uma das mais importantes conseqüências esperadas com o FUNDEF. Em vista desse fenômeno, a própria legislação

\section{Tabela 2}

\section{Mapa da municipalização do ensino fundamental no Paraná em 2002}

\begin{tabular}{|c|c|c|c|c|c|c|c|c|}
\hline Aro & $\begin{array}{l}\text { Deperndência } \\
\text { Administr. }\end{array}$ & $\begin{array}{l}\mathcal{N} \\
\text { Estabelec. }\end{array}$ & $\begin{array}{l}\% \\
\text { Estabelec. }\end{array}$ & $\mid \begin{array}{l}\text { NaAunos } \\
1^{\mathrm{a}} \mathrm{a} 4^{\mathrm{a}} \text { Série }\end{array}$ & $\mid \begin{array}{l}\% \text { Alunos } \\
1^{1} \mathrm{a} 4^{\mathrm{a}} \text { Série }\end{array}$ & $\begin{array}{l}N \\
\text { Muniápios }\end{array}$ & $\begin{array}{l}\text { Muriápios } \\
\text { Stulaçäo }\end{array}$ & $\begin{array}{l}\% \\
\text { Maniápios }\end{array}$ \\
\hline \multirow[t]{3}{*}{1999} & Estadual & 451 & $23 \%$ & 129.070 & $14 \%$ & 24 & $\begin{array}{l}\text { Năo } \\
\text { municipalizados }\end{array}$ & $6 \%$ \\
\hline & Municipal & 1.529 & $77 \%$ & 769.074 & $86 \%$ & 32 & $\begin{array}{l}\text { Parcialmente } \\
\text { municipalizados }\end{array}$ & $8 \%$ \\
\hline & & & TOTAL & 898.144 & & 343 & $\begin{array}{l}\text { Tdatherte } \\
\text { muricporizados }\end{array}$ & $86 \%$ \\
\hline \multirow[t]{3}{*}{2000} & Estadual & 322 & $16 \%$ & 105.778 & $12 \%$ & 18 & $\begin{array}{l}\text { Näo } \\
\text { municipalizados }\end{array}$ & $5 \%$ \\
\hline & Municipal & 1.658 & $84 \%$ & 761.136 & $88 \%$ & 28 & $\begin{array}{l}\text { Parcialmente } \\
\text { municipalizados }\end{array}$ & $7 \%$ \\
\hline & & & TOTAL & 866.914 & & 353 & $\begin{array}{l}\text { Totanate } \\
\text { muriciparizados }\end{array}$ & $88 \%$ \\
\hline \multirow[t]{3}{*}{2001} & Estadual & 248 & $13 \%$ & 70.708 & $8 \%$ & 5 & $\begin{array}{l}\text { Não } \\
\text { municipalizados }\end{array}$ & $1 \%$ \\
\hline & Municipal & 1.732 & $87 \%$ & 768.523 & $92 \%$ & 12 & $\begin{array}{l}\text { Parcialmente } \\
\text { municipalizados }\end{array}$ & $3 \%$ \\
\hline & & & TOTAL & 839.231 & & 382 & 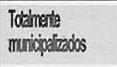 & $96 \%$ \\
\hline \multirow[t]{3}{*}{2002} & Estadual & 181 & $9 \%$ & 49.211 & $6 \%$ & 3 & $\begin{array}{l}\text { Nāo } \\
\text { municipalizados }\end{array}$ & $1 \%$ \\
\hline & Municipal & 1.799 & $91 \%$ & 783.725 & $94 \%$ & 7 & $\begin{array}{l}\text { Parcialmente } \\
\text { municipalizados }\end{array}$ & $2 \%$ \\
\hline & & & TOTAL & 832.936 & & 389 & $\begin{array}{l}\text { Totaneate } \\
\text { municipiarados }\end{array}$ & $97 \%$ \\
\hline
\end{tabular}

Fonte: PARANÀ. Secretaria de Estado da Educação (2002).

*Estabelecimentos Municipalizados. 
que criou o Fundo prevê a transferência de escolas entre as redes e a correspondente transferência de recursos financeiros sob a celebração de convênios específicos entre governos envolvidos, na forma prevista na Lei n ${ }^{\circ}$ 9.424/96 (BRASIL, 1996).

No Paraná, em 2002, são 389 municípios ou $97 \%$ de toda a rede de $1^{\mathrm{a}}$. a $4^{\mathrm{a}}$. série municipalizada, contando inclusive com alguns projetos isolados de municipalização de $5^{\mathrm{a}}$ a $8^{\mathrm{a}}$. série. No quadro abaixo vemos o mais recente retrato da municipalização de $1^{\mathrm{a}}$. a $4^{\mathrm{a}}$. série do ensino fundamental no Estado do Paraná.

O município de Londrina enquadra-se entre os 3\% dos municípios que ainda resistem à municipalização do ensino fundamental, entre os $97 \%$ dos que já municipalizaram toda sua rede de $1^{\text {a }}$. a $4^{\text {a }}$. série no Paraná. Percebemos que, não obstante a prefeitura de Londrina estar aplicando, em educação, valor maior do que pedem os preceitos constitucionais e ter ganhos com o FUNDEF, ela não adere à Municipalização total e afirma que a mesma pode acarretar problemas financeiros ao município, com o aumento em gastos com recursos humanos.

Através da pesquisa percebemos que, apesar de algumas opiniões de adesão tomadas isoladamente, os Sindicatos (APP-Sindicato e SINDSERV), o atual Conselho Municipal de Educação e as duas gestões da Secretaria Municipal de Educação do Partido dos Trabalhadores (1992/ 1996, 2000/atual) colaboram para a perpetuação dessa resistência. Nesse contexto, no período de 1995 a 2002, Londrina municipalizou apenas cinco das mais de trinta escolas estaduais de $1^{\text {a }}$. a $4^{\text {a }}$. série do ensino fundamental pertencentes ainda hoje à rede estadual, um cenário que a diferencia das demais cidades do norte paranaense.

A atual Secretaria Municipal de Educação é vista como órgão de maior poder nesse processo de resistência, apesar da chamada "Municipalização Branca"1 vir ocorrendo gradativamente no município.

Segundo documentação constituída por membros da atual Secretaria Municipal de Educação que (LONDRINA, 1995), participaram do projeto de municipalização da 1a . Escola Estadual (Escola João XVIII),

\footnotetext{
${ }^{1}$ A expressão Municipalização Branca é utilizada pelo SINDSERV (Sindicato dos Servidores Municipais de Londrina) para designar a municipalização não institucionalizada que vem ocorrendo em Londrina.
} 
"pouca ou quase nenhuma melhoria foi proporcionada pelo mecanismo da municipalização do ensino fundamental em Londrina, o que não permite denominá-lo de processo democrático".

Através do documento "Proposta Preliminar para Municipalização do Ensino de $1^{\text {a }}$ a $4^{\text {a }}$. série do Ensino Fundamental - Rede Física" (LONDRINA, 1998), também chamada Contra-Proposta da Municipalização, a SME da prefeitura do município de Londrina (gestão 92/96) explica que, embora não tivesse tido, por parte do município de Londrina, uma formalização da Municipalização do ensino fundamental, esta já era sentida, uma vez que em muitas regiões o ensino de $1^{\text {a }}$ a $4^{\text {a }}$. série foi sendo assumido gradativamente pelo município, "às vezes com o discurso de este estar mais próximo da comunidade e, principalmente, pelo fato do Estado congelar esse atendimento". (LONDRINA, 1998, p.4)

Em termos formais, o processo de municipalização do ensino fundamental na cidade de Londrina inicia-se em junho de 1995 com o estabelecimento do Termo Cooperativo de Parceria Educacional n. 175/ 95, firmado entre a Secretaria de Estado da Educação e a prefeitura do município de Londrina.

Segumdo a Broposta Breliminar para Municipalização do ensino de $1^{\text {a }}$ a $4^{\text {a }}$. série do ensino fundamental (LONDRINA, 1998, p.3), a municipalização do ensino fundamental de $1^{\mathrm{a}}$. a $4^{\mathrm{a}}$. série foi conduzida pela prefeitura, de forma gradativa e na medida da capacidade de absorção pelo município, com a finalidade de evitar o desequilíbrio econômico da cidade e o comprometimento com a qualidade de ensino.

Além de gradativa, de acordo com representantes da atual Secretaria Municipal de Educação de Londrina, a municipalização foi discutida amplamente com os professores da rede. Os mesmos participaram da elaboração da contra-proposta da municipalização, pedindo reformulações. Essa informação é debatida também pela Assessoria de Planejamento.

De acordo com a Assessoria de Planejamento, a proposta de municipalização foi debatida em conjunto pelos professores da rede, musito antes da municipalização formal das primeiras escolas. "Foi após muito debate que, em 1998, a SME enviou à Secretaria de Estado da Educação do Paraná uma contra-proposta de municipalização, exigin- 
do reformulações, melhorias na rede física e estrutura para dar encaminhamento à política de descentralização administrativa" (Relatos da atual Assessoria de Planejamento).

Londrina vem resistindo à municipalização do ensino desde 1989. $\mathrm{Na}$ intenção da SEED/Paraná toda a rede estadual de $1^{\mathrm{a}}$. a $4^{\mathrm{a}}$. série já estaria municipalizada, antes mesmo da nova LDB entrar em vigor em 1997.

A contra-proposta da municipalização de $1^{\mathrm{a}}$. a $4^{\mathrm{a}}$. série, apresentada pela SME/Londrina à SEED/PR em 1998, constituiu-se também um estudo sobre as necessidades de adequações, ampliações e construções de escolas no município, assim como a eliminação de dualidades administrativas, visando a continuidade do processo de municipalização do ensino de $1^{\mathrm{a}}$. a $4^{\mathrm{a}}$. série, apenas se ela fosse encaminhada de forma diferenciada daquela que vinha sendo proposta pelo Estado do Paraná.(LONDRINA, 1998, p.5)

Um segundo fator parece explicar também a resistência da SME à municipalização em Londrina. A explicação está em que a SEED/PR, em 2002, não responde à Proposta Preliminar ou Contraproposta da municipalização, enviada pela SME de Londrina em 1998. Caso esta tivesse sido respondida, a SME teria formulado um novo documento, desta vez, um estudo das condições humanas do município para a continuidade (ou não) do processo de municipalização.

A Proposta Preliminar para a municipalização do ensino de $1^{\mathrm{a}}$. a $4^{\mathrm{a}}$. série do ensino fundamental de Londrina apresenta uma contrapartida ao governo do Estado do Paraná, aceitando a municipalização, que parecia irreversível, em "fases harmônicas", a fim de não causar rupturas econômicas e pedagógicas no município.

O referido documento propõe três fases de trabalho para a aceitação da municipalização do ensino:

a) Fase I: ano letivo de 1996: foram municipalizadas as escolas estaduais João XVIII, Eurides Cunha e Arthur Thomas, cujos prédios pertenciam ao setor público estadual, passando à dependência administrativa ao município. No mesmo ano foi também assumido pelo município o ensino de $1^{\mathrm{a}}$. a $4^{\mathrm{a}}$. série da Associação Acalon, administradora da Escola Oficina; 
b) Fase II: ano letivo de 1999: dando continuidade ao processo de municipalização, a prefeitura propõe-se assumir o ensino de $1^{\mathrm{a}}$. a $4^{\mathrm{a}}$. série do distrito de São Luiz, passando a Escola Estadual Capitão Eusébio Barbosa de Menezes a funcionar em dualidade administrativa, continuando o atendimento de $5^{\mathrm{a}}$. a $8^{\mathrm{a}}$. série sob responsabilidade estadual;

c) Fase III: segundo a Secretaria Municipal de Educação, a continuidade do processo dependerá das negociações entre as partes e da garantia de recursos físicos, humanos e financeiros, necessários ao bom funcionamento das escolas.

De acordo com o Termo de Parceria Educacional n. 175/95, firmado entre a Secretaria de Estado da Educação do Paraná e a Secretaria Municipal de Educação de Londrina, o município de Londrina, agora como "Município-Parceiro", passa a se comprometer, de "forma irreversível", prioritariamente, com as quatro séries iniciais, com toda a educação especial e com o supletivo fase 1 (LONDRINA, 1995, p.3).

Tomando por base a relação entre as exigências feitas pelo Governo do Estado do Paraná à SME de Londrina em 1995, através do Termo de Parceria Educacional, e o texto da Contra-proposta da Municipalização construído pela SME de Londrina, podemos afirmar que a intenção da SME em municipalizar apenas cinco escolas, de 1995 a 2002, tem como objetivo político harmonizar as pressões políticas e se comprometer com uma pequena parcela, a fim de encerrar, por algum tempo, uma pressão que vinha sendo exercida pela SEED/PR sobre a SME/Londrina.

A municipalização proposta pelo governo do Paraná em 1995 acarretaria para a prefeitura de Londrina o compromisso automático da manutenção ou construção de prédios, a contratação de professores e a responsabilidade com todos os demais recursos humanos e financeiros para com as escolas municipalizadas.

Apesar da resistência explicitada nos documentos e nas falas dos atores, a municipalização pode ser percebida na distinção do número de matrículas de alunos do ensino fundamental entre a rede municipal e a rede estadual. De acordo com a SME, o crescimento do número nesta modalidade de ensino na rede municipal mostra que ocorre, em Londrina, uma municipalização não-formalizada. 
Já existe a "municipalização não-formal" em Londrina, pois enquanto o governo do Estado do Paraná se compromete com pouco mais de 8.000 alunos do ensino fundamental, a prefeitura do município de Londrina é responsável por 35.000 alunos aproximadamente, contando com alunos de $5^{\mathrm{a}}$. a $8^{\mathrm{a}}$. série que, nos distritos administrativos, são assumidos pela prefeitura; uma quantidade que cresce a cada momento para a SME.

Os quadros abaixo ilustram essa ascensão de matrículas do ensino fundamental de $1^{\mathrm{a}}$. a $4^{\mathrm{a}}$. série no município e ajuda a compreender a denominada "municipalização branca" ou "municipalização não-formal". No primeiro quadro, o número de alunos matriculados de $1^{\mathrm{a}}$. a $4^{\mathrm{a}}$. série do ensino fundamental em Londrina, em 1999.

\section{Quadro 1}

Alunos matriculados no ensino fundamental de $1^{\text {a }}$ a $4^{\text {a }}$ série, em 1999, Londrina

\begin{tabular}{|c|c|c|c|}
\hline $\begin{array}{l}\text { Modalidades } \\
\text { de Ensino }\end{array}$ & ESTADUAL & MUNICIPAL & MUNICIPALIZADA \\
\hline $\begin{array}{l}1^{\text {a }} \text { a } 4^{\mathrm{a}} \text {. série } \\
\text { Pré-escolar } \\
\text { Educação Especial } \\
\text { Total }\end{array}$ & $\begin{array}{l}8.997 \\
228 \\
221 \\
9.446\end{array}$ & $\begin{array}{l}23.308 \\
2.727 \\
12 \\
26.047\end{array}$ & $\begin{array}{c}621 \\
101 \\
11 \\
933\end{array}$ \\
\hline
\end{tabular}

Fonte: Núcleo Regional de Educação (2002).

\begin{tabular}{|c|c|c|}
\hline \multicolumn{3}{|l|}{ Quadro 1} \\
\hline \multicolumn{3}{|c|}{$\begin{array}{l}\text { Alunos matriculados no ensino fundamental } \\
\text { de } 1^{a} \text { a } 4^{a} \text { série, em 2002, Londrina }\end{array}$} \\
\hline Modalidades & ESTADUAL & $\begin{array}{l}\text { MUNICIPAL (incluíndo as } \\
\text { escolas municipalizadas) }\end{array}$ \\
\hline $\begin{array}{l}1^{\text {a }} \text {. a } 4^{\text {a }} \text {. série } \\
\text { Pré-escolar } \\
\text { Educação Especial } \\
\text { Total }\end{array}$ & $\begin{array}{l}7.885 \\
164 \\
202 \\
8.251\end{array}$ & $\begin{array}{l}23.770 \\
3.246 \\
102 \\
27.118\end{array}$ \\
\hline
\end{tabular}


Em relação ao número de alunos matriculados no ensino fundamental no Estado e no município, nos dois quadros, chama a atenção o aumento da responsabilidade do município de Londrina pela educação de $1^{\text {a }}$. a $4^{\text {a }}$. série como um todo. No segundo quadro, em específico, a ênfase recai sobre o aumento do número de matrículas de alunos de $1^{\mathrm{a}}$. a $4^{\mathrm{a}}$. série da educação especial nas escolas do município.

Pelos quadros da educação fundamental em Londrina podemos perceber que a gradativa responsabilização do município pelo ensino fundamental de $1^{\text {a }}$. a $4^{\mathrm{a}}$. série não se restringe à municipalização formal.

Mas, dados do Projeto Acompanhamento da Implantação do Fundo (2002) demonstram que o número de matrículas, de 1996 a 2002 , na rede municipal cresce pouco $(4,4 \%)$. Duas razões podem ser pensadas. A primeira vem da emancipação do Distrito de Tamarana em 1997, levando com ela uma média de 1.877 alunos. A segunda explica-se pela nucleação das escolas isoladas na zona rural de Londrina. A educação especial (de 1997 a 2000, 77\% de vagas a mais foram oferecidas pelo município) e a educação de jovens e adultos de $1^{\mathrm{a}}$. a $4^{\mathrm{a}}$. série (aumento de 686 novas matrículas), na rede municipal, foram as modalidades que mais cresceram.

Apesar do aumento pouco expressivo do número de matrículas da rede municipal, quando comparamos o mesmo dado com a rede estadual vemos um crescimento muito mais expressivo. O Estado só atende $25 \%$ dos alunos do ensino fundamental na cidade de Londrina. Esse aumento, quando comparado ao da rede estadual, pode ser explicado pela lógica do FUNDEF que redistribui os recursos arrecadados de acordo com o número de matrículas no ensino fundamental. Esse aumento de vagas atinge principalmente a zona urbana. A zona rural, além da nucleação das escolas isoladas, passa por questões de ordem mais abrangente como a modernização agrícola e o êxodo rural.

De acordo com a proposta da LDB de 1996, os municípios devem responsabilizar-se também por toda educação especial. No Termo Cooperativo de Parceria Educacional de 1995, firmado entre a SME e a SEED/PR, esta exigência é destacada. (LONDRINA, 1995). 
A superintendência de Educação e o Departamento de Educação Especial da Secretaria de Estado da Educação, considerando: que os princípios de universalização e democratização do ensino só serão obedecidos através do efetivo atendimento aos alunos portadores de necessidades educacionais especiais, [...] o investimento realizado pelo Estado do Paraná na capacitação de recursos humanos para a área da Educação Especial e a proposta de parceria responsável Estado/município para dar cumprimento aos dispositivos legais, no que concerne ao Ensino Fundamental, [...] resolvem: o Ensino Especial, parte integrante do Ensino Fundamental, deverá ser contemplado no processo de municipalização do ensino, de conformidade com a legislação Federal e Estadual em vigor [...] (PARANÁ, 1995).

De acordo com o Termo Cooperativo de Parceria Educacional, a criação, a autorização de funcionamento, o reconhecimento, a inspeção e a cessação do funcionamento das modalidades e programas de educação especial no processo de municipalização, devem seguir as orientações contidas na Deliberação 020/86, cabendo ao Departamento de Educação Especial da SEED/PR o pronunciamento conclusivo nesses processos. $\mathrm{O}$ documento diz ainda que o encaminhamento do aluno portador de deficiências especiais de educação deve ser precedido de uma avaliação diagnóstica multidisciplinar, realizada por uma equipe de profissionais habilitados da SME ou do NRE.

Em Londrina a SME não assume de imediato a responsabilidade pelas unidades de educação especial da rede estadual. Da mesma forma que ela vai assumindo gradativamente os alunos do ensino fundamental de $1^{\text {a }}$. a $4^{\text {a }}$. série das escolas estaduais, ela vai assumindo também a educação especial.

$\mathrm{Na}$ rede estadual de Londrina, essa modalidade de ensino não tem recebido do governo do Estado do Paraná estrutura adequada para um funcionamento de qualidade. São muitas as dificuldades enfrentadas pelos professores que trabalham com a educação especial. As maiores dizem respeito à falta de material pedagógico, à ausência de cursos de formação continuada, específicos para a educação especial, à não-contratação de novos professores, ao número excessivo de crianças em sala, ao fechamento de salas, ao deficiente acompanhamento 
da avaliação individual das especialidades dos alunos. É possível relacionar todos esses fatos ao que denominamos de municipalização forçada da educação especial em Londrina.

Em relação à qualificação de recursos humanos, podemos afirmar que a SME de Londrina, de 1995 a 2002, investiu muito mais em cursos de formação continuada e de capacitação dos professores de educação especial que a SEED/PR, através do Núcleo Regional de Educação de Londrina. Outro dado que pudemos constatar com a pesquisa, no caso londrinense, é que não há uma municipalização formal da educação especial,uma vez que ela se restringe aos alunos de educação especial das cinco escolas municipalizadas, de 1995 a 2002, porém, tanto o aumento gradativo do número de matrículas para o município, como a diminuição gradativa do número de salas de D.E. e D. F. na rede estadual, mostram que a municipalização da educação especial em Londrina vem ocorrendo de forma não- institucionalizada. O Estado do Paraná não abre concurso para professores de $1^{\mathrm{a}}$. a $4^{\mathrm{a}}$. série há mais de dez anos, ocorrendo o mesmo com a educação especial.

De acordo com o Núcleo Regional de Educação de Londrina, não há concursos públicos para contratação de professores de $1^{\mathrm{a}}$. a $4^{\mathrm{a}}$. série, mas a Agência Paranaeducação vem contratando professores todos os anos. É importante pensar que os profissionais contratados pela Agência não gozam da mesma estabilidade que os concursados. Para nós, a não-realização de concursos públicos para professores de $1^{\text {a }}$. a $4^{\text {a }}$. série do ensino fundamental para a rede estadual explica a intenção do Estado de transferir a rede fundamental de $1^{\text {a }}$ a $4^{\mathrm{a}}$. série para os municípios, ou o desejo de que a prefeitura municipalize todas as escolas da rede estadual, já que a LDB induz a essa responsabilidade.

É importante frisar ainda que, estabelecida a municipalização entre as partes (Estado e município), o município não é obrigado a assumir os professores não-concursados. O Estado os remaneja ou remove por algum tempo. Se paulatinamente as escolas estaduais de $1^{\text {a }}$ a $4^{\text {a }}$. série vão sendo transferidas para a responsabilidade do município, através da "municipalização branca" ou através da municipalização formal, e se desde 1986 não há concursos para pro- 
fessores do ensino fundamental de $1^{\mathrm{a}}$. a $4^{\mathrm{a}}$. série da rede estadual, podemos dizer que chegará o momento em que os professores celetistas (maioria), impedidos de se efetivarem, serão gradativamente demitidos pela municipalização em Londrina. Tanto o professor quanto o pessoal técnico-administrativo passa, desde já, a conviver com essa insegurança e instabilidade no trabalho em virtude dessa política educacional.

De acordo com o NRE/Londrina, não há problemas para os professores da $1^{\text {a }}$ a $4^{\mathrm{a}}$. série com a municipalização: os concursados não perdem seus direitos e os celetistas são removidos ou assumidos por outra escola de $1^{\text {a }}$. a $4^{\text {a }}$ série da rede estadual. (LONDRINA. Núcleo Regional de Educação, 2002)

Para a APP-Sindicato de Londrina, essa insegurança significa a perda de direitos conquistados pela luta dos professores do Paraná, luta por melhores condições de trabalho, salários mais dignos, maior investimento na educação pública e melhores resultados na qualidade do ensino (Relatos da APP-Sindicato).

A APP-Sindicato de Londrina entende a municipalização de ensino como uma proposta problemática para a educação, também por outras razões, tais como: a SEED/PR não ouve as proposições dos professores e de suas organizações representativas, a municipalização não aumenta os recursos públicos para a educação básica e, ainda, a política de financiamento exclui de seu orçamento a educação infantil, a educação especial e a educação de jovens e adultos. Para a entidade a municipalização atropela direitos adquiridos.

A política de financiamento da municipalização não se restringe ao FUNDEF; essa deve ser interpretada de forma mais ampla, dada a fragilidade do processo de municipalização ainda apresentar forte dependência (com relação ao repasse) de recursos financeiros do Estado, da cessão de professores estaduais para as escolas municipalizadas e do repasse de recursos para a manutenção de prédios.

Pesquisas do IPARDES, anteriores à nova LDB, mostram que em 1994, o Estado ainda não havia sentido um impacto positivo em suas despesas a partir da municipalização do ensino, nem os municípios tinham-se estruturado o suficiente para assumir como responsabilidade o ensino de $1^{\mathrm{a}}$ a $4^{\mathrm{a}}$. série (IPARDES, 1994, p.3). 
O mesmo documento acrescenta:

a fase atual do processo de municipalização tem como herança procedimentos pouco claros e falta de critérios em sua condução, que acabam por ocasionar muitos problemas e inquietações sobre a sua continuidade, ou seja, as sucessivas tentativas do Estado de repassar atribuições aos municípios resultaram em relações conflituosas, nunca enfrentadas visando à confluência de interesses. (IPARDES, 1994, p. 4)

Se pensarmos no pós-LDB/96, como uma segunda fase do processo de municipalização do ensino fundamental no Paraná, para o caso de Londrina, podemos afirmar que o documento do IPARDES (1994) ainda serve para explicar, em parte, os problemas detectados com a municipalização.

Segundo o ex-secretário da educação (gestão 92/96), então secretário no ato da municipalização das primeiras escolas, um dos maiores problemas enfrentados pela prefeitura com a municipalização foi o reduzido número de professores concursados fornecidos pelo Estado às escolas municipalizadas, a não-transferência de toda a estrutura física das escolas estaduais ao município e a ausência de um planejamento integrado entre a SME e a SEED, anterior à assinatura do Termo de Parceria.

De acordo com o entrevistado, a prefeitura precisou abriu concursos para professores de $1^{\text {a }}$. a $4^{\text {a }}$. série a fim de sanar as carências de recursos humanos, advindas com a municipalização.

Para 2002, o município de Londrina terá que assumir, paulatinamente, a educação infantil, responsabilizando-se, em média, por 60 creches sustentadas hoje, em grande medida, por redes filantrópicas, com uma média de 4.000 crianças. Por outro lado, no novo financiamento do FUNDEF, não há verbas específicas para a educação infantil.

O FUNDEF é um dos grandes indutores da municipalização do ensino fundamental e a Emenda Constitucional n. 14 de 1996 (BRASIL, 1996b) constitui-se na reforma mais significativa efetivada no financiamento da educação, de modo particular no ensino fundamental. "A principal crítica a esta reforma reside no seu caráter apenas redistributivo e por não acrescentar novos aportes de recursos para a educação, em 
especial à educação infantil e à educação de jovens e adultos" (UNIVERSIDADE FEDERAL DO PARANÁ, 2002b, p.3).

A municipalização do ensino em Londrina representa apenas transferência de responsabilidades e serviços, não de autonomia, poder e aumento do montante de recursos a serem aplicados no ensino.

O ex-secretário da educação (gestão 92/96) conta que em 1995 a proposta do governo do Estado era que a prefeitura de Londrina assumisse todas as escolas de $1^{\text {a }}$ a $4^{\text {a }}$. série do município, segundo ele, número e ônus que excedia à capacidade da Secretaria Municipal de Educação. O que fez a prefeitura foi municipalizar algumas escolas para conseguir um período de tranqüilidade em meio às cobranças políticas e administrativas do Estado do Paraná.

Interessante é notar que o que ocorreu no caso londrinense destoa dos acordos oficiais feitos inicialmente com os municípios, para que os mesmos aderissem ao projeto de municipalização. De acordo com o Termo Cooperativo de Parceria Educacional, a ser firmado entre a Secretaria de Estado da Estado da Educação e os municípios parceiros, a partir de 1991, o objetivo era ceder os servidores estaduais e/ou recursos para a rede municipal de ensino e desenvolver ações conjuntas, definindo as condições em que se processaria a transferência de recursos técnicos financeiros estaduais destinados a manutenção da rede municipal de ensino.

Há dois pontos a serem ressaltados nesse documento. Primeiro, o documento só considera aspectos financeiros e implicações administrativas. Segundo, analisando o Termo de Cooperação, as atribuições da SEED e do Município Parceiro, não vemos indicações claras quanto à organização de um sistema estadual de educação, a uma política salarial, a uma gestão democrática da escola, a diretrizes curriculares, à promoção de concursos públicos, aos critérios de remoção e contratação de professores, à formação ou qualificação profissional, ou seja, há a falta de critério quanto ao padrão de qualidade da rede pública de ensino (SANTOS, 1998, p.220).

Mesmo considerando as deficiências do documento, a municipalização das primeiras escolas em Londrina parece destoar-se dele. O Estado parece não ter ouvido, a contento, as necessidades da $\mathrm{SME} /$ Londrina e não se preocupou com os desafios, as inseguranças e as consequiências que seriam geradas, apenas apoiou-se na Lei. 
Santos, em suas pesquisas sobre a descentralização educacional no Paraná, verificou que um dos pontos preocupantes da municipalização foi a falta de uma avaliação preliminar das condições financeiras e pedagógicas dos municípios parceiros. Esta falta de aval parece ter ocorrido em Londrina: não foram avaliadas as condições estruturais e financeiras do município, não foram ouvidas as propostas dos professores e organizações, tampouco se pensou no novo direcionamento do processo pedagógico.

Além de não ouvir as necessidades da SME/Londrina, a SEED/ PR não aceitou, com a municipalização de $1^{\mathrm{a}}$. a $4^{\mathrm{a}}$. série, responsabilizar-se pelo ensino de $5^{\mathrm{a}}$. a $8^{\mathrm{a}}$. série que a prefeitura de Londrina oferece, com qualidade, nos distritos. Esperava-se com o acordo feito em 1995 que, ao assumir a rede de $1^{\text {a }}$ a $4^{\mathrm{a}}$, o Estado assumisse as escolas de $5^{\mathrm{a}}$. a $8^{\text {a }}$. série. A resposta da SEED/PR foi negativa.

Aqui evidencia-se mais um ponto de conflito entre a SEED/PR e a SME/Londrina. A recusa da SEED/PR em assumir as escolas de $5^{\text {a }}$. a $8^{\text {a }}$. série dos distritos parece ser mais uma razão para que a SME/Londrina não dê continuidade ao processo de implantação da municipalização do ensino.

O fato da nova LDB determinar que o ensino fundamental é prioridade da rede municipal de ensino possibilitou-nos ver uma espécie de jogo de forças que vem ocorrendo quanto a quem cabe a responsabilidade pelo ensino fundamental de $1^{\mathrm{a}}$. a $4^{\mathrm{a}}$. série em Londrina. Os problemas sofridos pelas escolas de $1^{\text {a }}$ a $4^{\text {a }}$. série da rede estadual, aos olhos dos representantes do Estado, parecem ter um culpado declarado: a Secretaria Municipal de Educação de Londrina que não assume o que determina a LDB de 1996. Nesse caso, a SME/Londrina passa a ser a responsável pelo progressivo abandono que vêm sofrendo essas escolas, sendo, então, acusada de omissão. Para a SME/Londrina, o Estado não cumpre com sua parcela de responsabilidade. Nesse conflito, os maiores perdedores parecem ser a escola, as crianças e a cultura democrática que, na prática, vai-se esvaziando.

A municipalização do ensino parece ocorrer, então, como uma leitura intencionada da LDB para transferir as responsabilidades e as despesas ao município-parceiro. A prova disso está no não-cumprimento da promessa de que a mesma se daria de forma gradual e numa 
negociação que beneficiasse ambas as partes.

Quanto à reivindicação do processo de implantação gradativo da municipalização, proposto e não cumprido pelo governo estadual, lembramos que ela aparece no documento da $\operatorname{AMEPAR}(1993$, p.6): "Reivindicamos a municipalização gradual, por séries ou por escolas e que ela resulte da negociação individualizada de cada município com o Estado e não a implicação de modo genérico e igual para todos no mesmo momento, como vem ocorrendo". (sic)

Essas questões vêm preocupando, de forma especial, a APP/ Sindicato do Paraná. Em entrevista com dirigentes da APP-Sindicato em Curitiba, o órgão afirma que as contradições financeiras e políticas da municipalização de ensino, erroneamente entendida como democratização da educação, foram e continuam sendo discutidas no Fórum Paranaense em Defesa da Escola Pública Gratuita e de Qualidade, do qual muitos professores da rede municipal e estadual de Londrina fazem parte.

O Fórum em Defesa da Escola Pública Gratuita e Universal (1991), no nível local e estadual, representa um dos maiores focos da resistência à municipalização do ensino. Os textos do Fórum traduzem a posição da entidade e de todas as organizações representativas que se opõem à municipalização do ensino.

Na V Sessão Plenária do Fórum, registrou-se um posicionamento relativo ao processo de municipalização traduzido no "Protocolo de Intenções". Segundo a entidade, o desencadeamento da municipalização no Paraná foi marcado pela falta de clareza em torno dos critérios e de discussões prévias e abrangentes. Essa resistência do Fórum quanto à municipalização também foi analisada por Jussara Santos (1998). Ela enumera os principais problemas anunciados pela entidade em maio de 1991;

[...] sobre o processo de implantação da municipalização do ensino: acentua e agrava a separação do ensino fundamental em dois blocos, ferindo a concepção de escola unitária e de padrão único de qualidade [...] não há condições de promover, implementar e manter uma política de aperfeiçoamento para os profissionais da educação, uma vez que, com a municipalização do ensino o estado vem se desobrigando da assistência técnico-pedagógica e pro- 
movendo uma assistência financeira insuficiente [...]. Sobre a carreira, o salário, o regime de trabalho e a organização dos profissionais da educação: [...] há falta de definição de qual instância arcará com o ônus na manutenção de pessoal administrativo e de serviços das escolas onde o Estado e o município mantenham classes [...] indefinição sobre o regime de trabalho, risco de perda de direitos já alcançados pela categoria e risco de esfacelamento da organização sindical (FÓRUM PARANAENSE... apud SANTOS, 1998, p.222).

Para os representantes do Fórum, o processo de municipalização do ensino não garante a democratização dos critérios de distribuição de verbas para a educação, tampouco o seu controle por parte da comunidade. Outra preocupação levantada pelo Fórum é o fato de que, em nenhum momento, a legislação federal e a estadual deixam de afirmar que os encargos educacionais do ensino fundamental e da educação infantil cabem às três esferas de poder, ou seja, em nenhum momento se configurou a transferência pura e simples dessa responsabilidade para a esfera municipal e a desobrigação do Estado por esta responsabilidade (FÓRUM PARANAENSE... 1991a, p.4).

O Fórum que, segundo relatos da APP-Sindicato, representa a voz dos que resistem à municipalização em Londrina, propõe, em 1991, medidas incisivas para a municipalização no Paraná: "Sustação, pela SEED/PR, de todas as medidas que compõem o processo de municipalização do ensino, convocação de um amplo debate sobre as experiências da municipalização [...] avaliação detalhada da política de municipalização implementada e dos mecanismos empregados na sua operacionalização" (FÓRUM PARANAENSE... 1991a, p.6).

A municipalização em Londrina e a forma como vem sendo implantada deixam claro que a sustação não ocorreu, ao contrário, parece ter ganhado força maior. Mas, segundo a APP-Sindicato, o documento continua representando a proposta defendida pela entidade. Por outro lado, o fato de ter municipalizado apenas cinco escolas de 1995 até 2002 mostra que o município de Londrina tem conseguido resistir ao processo, mesmo sendo pressionado pelo Estado do Paraná, através da "Municipalização Branca", a assumir gradativamente alunos do ensino fundamental da rede estadual. 


\section{Repensando o caso londrinense}

No quadro geral das aproximações legais, políticas, econômicas da realidade brasileira, a prática da municipalização do ensino fundamental de $1^{\text {a }}$. a $4^{\mathrm{a}}$. série, em Londrina, apresenta peculiaridades e características muito próprias. Ao olharmos para a singularidade desse fenômeno constatamos a evidência dos conflitos e do processo de resistência em torno desse mecanismo descentralizatório.

A destinação de uma parcela importante do FUNDEF para a capacitação e formação dos professores é vista como um avanço em termos de conquista democrática atrelada à municipalização do ensino. Outro ponto forte da política de descentralização educacional brasileira, da LDB de 1996, quanto à municipalização e à nova política de financiamento público disponibilizada para a educação é, sem dúvida, a abertura para a criação dos conselhos municipais. A efetivação dos conselhos representa um ganho para a democratização educacional.

O Conselho de Acompanhamento e Controle Social do FUNDEF em Londrina, instituído pela Lei Municipal n. 7.297/97, representa um ganho para a democratização educacional. O Conselho Municipal de Educação cumpre papel tão importante, ou talvez até mais importante, que o Conselho de Acompanhamento e Fiscalização do FUNDEF. Além de deliberar a respeito das prioridades que devem reger a política municipal, o Conselho Municipal de Educação, ao representar os profissionais da educação, as diversas entidades desses profissionais e a sociedade organizada como um todo, pode propor e definir rumos bem mais significativos para a política educacional no espaço local.

Mas, embora a Lei Orgânica do município preveja a criação do Conselho Municipal de Educação e o município possua um grande número de escolas particulares e das escolas municipais de $1^{\text {a }}$. a $8^{\text {a }}$. série do ensino fundamental (mais de 60 atualmente), e tenha assumido algumas escolas da rede estadual de $1^{\mathrm{a}}$. a $4^{\mathrm{a}}$. série e sejam crescentes as

\footnotetext{
${ }^{2}$ Análises do impacto do FUNDEF no município de Londrina, realizadas pela Proposta do Projeto de Pesquisa "Processo de Implantação do FUNDEF em Estados e Municípios: casos e comparações com vistas a uma avaliação" (UNIVERSIDADE FEDERAL DO PARANÁ, 2002), pela Educação da Universidade Federal do Paraná, em parceria com outras IES brasileiras.
} 
matrículas para o ensino fundamental do município em contraposição às da rede estadual, o Conselho Municipal de Educação não forma ainda um Sistema Municipal de Ensino. O município possui não um sistema municipal, mas uma rede municipal de ensino, veiculada ao Sistema Estadual de Ensino do Paraná.

A implantação do FUNDEF foi bastante positiva para o município de Londrina, uma vez que o município ganha recursos do Fundo. Mas o município deixou de aplicar mais em educação depois de 1998, substituindo os recursos próprios por recursos vinculados ao FUNDEF (UNIVERSIDADE FEDERALDO PARANÁ, 2002b, p.35)².

A proposta mais viável de financiamento parece espelhar-se no Projeto de Lei do FUNDEB - Fundo de Manutenção e Desenvolvimento da Educação Básica Pública e de Valorização dos Profíssionais da Educação. Como modelo de financiamento e orçamento educacional, o projeto mostra-se como um modelo mais inclusivo e democrático. A nova proposta parece corrigir algumas falhas do FUNDEF, em especial a destinação de verbas para a educação infantil e a educação de jovens e adultos.

A municipalização era o que mais esperava o MEC. A própria legislação que criou o Fundo prevê a transferência de escolas de uma rede para outras e a correspondente transferência de recursos financeiros com a celebração de convênios específicos entre os governos envolvidos. Porém, em Londrina, diferentemente do que ocorreu no contexto paranaense ( $97 \%$ dos municípios com municipalização total), ela ainda sofre forte resistência.

Pela pesquisa, percebemos que alguns órgãos colaboraram significamente para a perpetuação dessa resistência: a atual Secretaria Municipal de Educação, o Sindicato dos Servidores Municipais de Londrina, o Sindicato dos Professores Estaduais e Municipais, o Conselho Municipal de Educação e o Fórum em Defesa da Escola Pública Gratuita e Universal no qual muitas dessas organizações mantêm representação.

Percebemos, pela pesquisa, que muitas razões da resistência à municipalização em Londrina têm sua origem nas normatizações do financiamento do ensino e nos conflitos em torno de outras atribuições que se dão no espaço macropolítico. 
Analisando os pontos de conflito e resistência, podemos pensar que o processo de municipalização pode estar criando uma segmentação dentro do ensino fundamental. Com a municipalização, embora o município tenha absorvido um número bastante elevado de matrículas, não se verificou uma conseqüente e adequada mudança organizacional na sua estrutura de ensino. O processo de municipalização pode estar provocando uma separação rígida, que não poderia haver no campo da educação pública, quanto às possibilidades de cada esfera do governo pela educação de $1^{\text {a }}$ a $4^{\mathrm{a}}$. série. A responsabilidade pelo ensino fundamental não é exclusiva dos municípios, aliás, a responsabilidade pela reformulação de políticas que irão refletir nas decisões municipais, é, em última instância, do Estado e da União.

A reflexão sobre a municipalização do ensino fundamental de $1^{\text {a }}$ a $4^{a}$. série em Londrina, sobre os conflitos e a resistência em torno da implantação dessa proposta, requer tanto a análise da relação entre Estado e descentralização, quanto do conceito conservador de descentralização que vem sendo incentivado pelo Estado do Paraná.

A municipalização é uma das modalidades da descentralização do Estado liberal e uma das principais características das novas reformas das políticas públicas educacionais no Brasil. A descentralização, assim como a municipalização, podem estar escondendo um desejo de privatização, de divisão de encargos e responsabilidades, sem a contrapartida da divisão de poder de decisão e aparato democrático da participação local.

Após analisar o processo de municipalização, podemos dizer que ele, assim como outras reformas descentralizadoras, não reflete um processo concomitante de autonomia relativamente às políticas educacionais. Torna-se evidente que a descentralização administrativa corresponde à centralização política, com graves conseqüências sobre o processo de controle público do poder. Há em curso uma desconcentração de serviços públicos sobrecarregando os municípios, sem haver, contudo, uma transformação significativa no padrão de gestão que possibilite a reestruturação desses serviços.

Se, por um lado, o avanço no processo de descentralização parece não significar, ainda, alcance setorial na capacidade de decisão, por outro lado, as decisões político-institucionais, ao nosso ver, não 
podem partir da suposição de que todas as regiões ou municípios estejam preparados, ao mesmo tempo e do mesmo modo, para encarregarse das novas atribuições. Nesse sentido, o processo de descentralização deve pautar-se pela flexibilidade da proposta e pelos critérios de compensação que levem em conta a situação peculiar de cada município.

A realidade nos mostra que, em detrimento da construção de um sistema nacional de educação, os municípios vão, aos poucos, constituindo seus próprios sistemas municipais de educação, mesmo sem dispor, muitas vezes, de recursos humanos para levar adiante essa responsabilidade. A pergunta que se faz é como ficará esse gerenciamento, quando os municípios pobres não puderem mais contar com os recursos do FUNDEF?

Enquanto este não seja o nosso propósito maior, a pesquisa do caso londrinense nos faz pensar que a relação entre descentralização e democratização, principalmente, a relação entre a municipalização do ensino fundamental e a democratização não é tão simples. Pensar nessas relações requer pensar em uma série de fatores que se entrelaçam. Para ser entendida como mecanismo democrático, a descentralização municipal precisa, basicamente, aproximar a administração da cidadania, garantir a participação do município e aumentar a representatividade do poder local e a forma de controle e de cooperação dos cidadãos.

Outros fatores precisam ser também levados em conta nessa relação entre municipalização do ensino e democracia: autonomia política e pedagógica; direito e poder de decisão; condições financeiras garantidas; valorização e legitimação dos canais de reivindicação pública; ampliação dos canais de planejamento; melhoria na remuneração de professores; aumento de investimentos para a educação pública; atendimento por parte do Estado das intervenções feitas pelas associações de professores; autonomia para as APMs; garantia de perpetuação de direitos conquistados; diálogo entre Estado e professores na implementação de reformas políticas para a educação; igualdade de condições políticas entre as diferentes instâncias de poder; inclusão educacional universal nos programas de financiamento: educação infantil e de jovens e adultos; universalização da educação; erradicação do analfabetismo; equalização de oportunidades educacionais e maior padrão de qualidade de ensino. Mesmo restringindo-nos a somente 
elencá-los nesse trabalho, essa tentativa pode ajudar-nos a entender que tais princípios não podem restringir-se também apenas às formas de financiamento e às medidas administrativas centralizadoras ou descentralizadoras no campo da política educacional. Discutir a municipalização e sua relação com a democracia é discutir projetos políticos de âmbito maior.

Entendemos que a opção pela descentralização é acima de tudo política, visto que o que está em jogo é o poder político, poder este que não pode ser pensado só no âmbito institucional do Estado, mas também no seio da sociedade civil.

A descentralização é condição necessária, mas não suficiente para a democratização do poder. Freqüentemente tem sido confundida a noção de descentralização com a de participação. Podemos até afirmar que a descentralização e a participação são políticas complementares de um mesmo processo, mas do mesmo modo é preciso entender que descentralização e participação são objetivos conceitualmente diversos e complexos.

A descentralização e a participação podem ser instrumentos políticos orientados para o desenvolvimento de uma política municipal de caráter democrático, desde que a descentralização seja orientada para além de uma medida estritamente funcional e não se limite à racionalização de recursos e a desburocratização estatal. Talvez ela pudesse estar mais próxima da democracia ou da democratização, se encarada como um meio para modificar a dinâmica vigente e para ampliar os canais de participação popular.

Uma questão se coloca neste debate. Com a municipalização do ensino, as ações das organizações passam a realizar-se no âmbito local. Se, por um lado, isso pode trazer benefícios, tais como a consolidação dos conselhos municipais e uma maior organização da participação no espaço local, por outro, faz com que muitas outras organizações representativas de profissionais da educação percam boa parte de sua capacidade de intervenção na elaboração das políticas nacionais e estaduais. Conseqüentemente há uma modificação das relações de força entre os diferentes setores sociais. Na sociedade capitalista cada vez mais internacionalizada em que vivemos, em que economia e política mostram-se ainda tão concentradas (ainda que às 
vezes apresentam formas descentralizadas de execução), descentralizar a organização dos trabalhadores para o âmbito municipal parecenos que seja um meio de também enfraquecê-los, uma vez que o poder econômico e político maior, decisivo, não é definido espacialmente, mas sim socialmente, pelas lutas de classes.

\section{Referências}

ASSOCIAÇÃO DOS PROFESSORES DO MÉDIO PARANAPANEMA. Reformulação do Processo de Municipalização do Ensino de $1^{\text {a }}$. a $4^{\mathrm{a}}$. série do $1^{\circ}$. grau. In: ENCONTRO DE DIRIGENTES MUNICIPAIS DE EDUCAÇÃO, 1993, Curitiba. Documentos... Curitiba: UNDIME/SEED, 1993.

BRASIL. Congresso Nacional. Lei 9.424, 24 de dezembro de 1996. Dispõe sobre o Fundo de Manutenção e Desenvolvimento do Ensino Fundamental e de Valorização do Magistério, na forma prevista no art. $60, \S 7^{\circ}$, do Ato das Disposições Constitucionais Transitórias e dá outras providências. Diário Oficial da Republica Federativa do Brasil, Brasília, 23 dez. 1996a

BRASIL. Congresso Nacional. Lei n. 9.394, 20 de dezembro de 1996. Lei de Diretrizes e Bases da Educação Nacional. Estabelece as diretrizes e bases da educação nacional. . Diário Oficial da Republica Federativa do Brasil, Brasília, 23 dez. 1996b.

BRASIL. MEC. Balanço do $1^{\circ}$. ano do FUNDEF: pesquisa por amostragem. Brasília, 1999.

BRASIL. Senado Federal. Emenda Constitucional n. 14, 12 de setembro de 1996, Modifica os artigos 34, 208, 211 e 212 da Constituição Federal e dá nova redação ao artigo 60 do Ato das Disposições Transitórias. Diário Oficial da Republica Federativa do Brasil, Brasília, 12 set. 1996c.

FORUM PARANAENSE EM DEFESA DA ESCOLA PÚBLICA, GRATUITA E UNIVERSAL. Relatório da V Sessão Plenária. Foz do Iguaçu, 1991a. Mimeo.

FORUM PARANAENSE EM DEFESA DA ESCOLA PÚBLICA, GRATUITA E UNIVERSAL. Pauta de proposições para a politica educacional do Estado do Paraná. Curitiba, 1991b. Mimeo.

INSTITUTO PARANAENSE DE DESENVOLVIMENTO ECONOMICO E SOCIAL - IPARDES. Temas Estratégicos para o Paraná. Curitiba, 1994.

LONDRINA. Núcleo Regional de Educação. Setor de Estatística. Estatisticas da municipalização. Londrina, 2002. 
LONDRINA. Prefeitura Municipal. Proposta preliminar para a municipalização do ensino de $1^{\mathrm{a}}$. A $4^{\mathrm{a}}$. Série do ensino fundamental, Rede Física. Londrina: Secretaria de Educação, 1998.

LONDRINA. Prefeitura Municipal. Termo de Parceria Educacional, n. 175/95. Firma a municipalização entre a Secretaria de Estado da Educação do Paraná e a Prefeitura Municipal de Londrina. Londrina, 1995

PARANÁ. Secretaria de Estado da Educação. Coordenação do Programa de Parceria Educacional. Relatório do Seminário sobre Política Educacional e Municipalização do Ensino. Curitiba, 1995.

PARANÀ. Secretaria de Estado da Educação. Núcleo de Parcerias Educacionais. Municipalização: $1^{\circ}$ segmento do Ensino Fundamental. Curitiba: SEE/PR, 2002.

PARANÁ. Superintendência de Educação. Departamento de Educação Especial. Termo Cooperativo De Parceria Educacional. Anexo I, Instrução Normativa Conjunta SUED/DEF, Anexo II, Critério para a condução da Educação Especial no processo de municipalização do ensino. Curitiba, 30 jun. 1995.

SANTOS, Jussara Maria T. Puglielli. As políticas Governamentais para o Ensino Fundamental do Paraná diante dos preceitos da Constituição. 1998. Tese (Doutorado) - Faculdade de Educação da Universidade de São Paulo, São Paulo.

SILVA, Ileizi Luciana Fiorelli. Reforma ou Contra-Reforma no Sistema de Ensino do Estado do Paraná? Uma análise da meta de igualdade social nas políticas educacionais dos anos 90 . In: Educação e Estado: as mudanças nos sistemas de ensino do Brasil e do Paraná na década de 90. Londrina: Editora da Universidade Estadual de Londrina, 2001. p.127-167.

UNIVERSIDADE FEDERAL DO PARANÁ Processo de Implantação do FUNDEF em Estados e Municipios: casos e comparações com vistas a uma avaliação. Curitiba: Setor de Educação, 2002b.

UNIVERSIDADE FEDERAL DO PARANÁ. Acompanhamento da Implantação do Fundo de manutenção e desenvolvimento do Ensino Fundamental e de valorização do Magistério no Estado do Paraná. Curitiba: Setor de Educação, 2002a. 


\section{Abstract}

The article intends to analyses the municipalization of the fundamental teaching process in Londrina, on the second half of the decade of ninety, anda over all, the process of resistance to this politic of decentralization, undertaken by social actors, organizad through their representative entities and through the municipal education office. The analysis helps us to comprrehend the relation ships of the local power and of the particularity of the education politic of the municipal district and of the aproximation of this politic to the reforms of descentralization stimulated in the national and state ambit.

Key words: Municipalization, Local Power, Politic Descentralization. 